How to cite: Beilicci, R.F., Beilicci, E.B.M. (2021) Advance Hydraulic Modelling of Barzava River, Romania, Caras Severin County. 2021 "Air and Water - Components of the Environment" Conference Proceedings, ClujNapoca, Romania, p. 181-188, DOI: 10.24193/AWC2021_17.

\title{
ADVANCE HYDRAULIC MODELLING OF BARZAVA RIVER, ROMANIA, CARAS SEVERIN COUNTY
}

\author{
Robert Florin BEILICCI ${ }^{1}$, Erika Beata Maria BEILICCI ${ }^{1}$ \\ DOI: 10.24193/AWC2021_17
}

\begin{abstract}
Study case is situated in Caras Severin county. To solve theoretical problems of movement of water in the river Barzava, it requires modelling of water flow in this case. Numerical modelling was performed using the program MIKE11. Advanced computational modules are included for description of flow over hydraulic structures, including possibilities to describe structure operation. The Hydrodynamic (HD) module is the nucleus of the MIKE 11 modelling system and forms the basis for most modules including Flood Forecasting, Advection-Dispersion, Water Quality and Non-cohesive sediment transport modules. The MIKE 11 HD module solves the vertically integrated equations for the conservation of mass and momentum, i.e. the Saint-Venant equations. The input data are: area plan with location of cross sections; cross sections topographical data and roughness of river bed; flood discharge hydrograph. Advanced computational modules are included for description of flow over hydraulic structures, including possibilities to describe structure operation. After simulation with MIKE 11 result the water level in each cross section.
\end{abstract}

Keywords: numerical modelling, hydraulic structures, Bârzava river, MIKE 11.

\section{INTRODUCTION}

The Barzava River is 85 kilometers long. It springs from the Semenic Mountains (at a distance of 5 kilometers upstream from Resita Municipality), passes through the localities: Mun. Resita, Bocsa, Berzovia, crosses the national road BelgradeTimisoara, about 4 kilometers from Deta crosses the border with Serbia and flows into the river Timis (Serbia) about 30 kilometers from the border.

In the area studied or performed hydrological and topographic measurements on the watercourse and the nature of the land, these measurements were the basis for the numerical modelling of the watercourse by the method of finite differences.

At the end of 1985, the first phase of complex arrangement of the watercourse of the Barzava river, between Resita Municipality and Gataia locality to the RomanianSerbian border, was completed.

Within this arrangement, regularizations were carried out, dams on the watercourse, the Ghertenis Polder was also made. these sectors. As a result, there were pronounced active erosions leading to the formation of gaps in the defense dams.

\footnotetext{
1 Hydrotechnics Department, Civil Engineering Faculty, Politehnica University of Timisoara, Timisoara, Spiru Haret 1A, 300022, ROMANIA, robert.beilicci@upt.ro
} 
The Ghertenis polder aimed to attenuate the flood wave on the Barzava river.

Currently there are 15 bridges that were built over the river Barzava.

Over time, due to the floods that occurred, as well as other administrative causes of circumstance, the hydrotechnical development works were affected, among which we mention:

- the bottom sills were damaged and destroyed,

- the defense dams were affected on certain sections, being eroded mainly as a result of the digression of the minor riverbed in horizontal and vertical plane, thus undermining their foundation and section. This was also due to the lack of shore consolidations in the exterior arrangements in the area of elbow cuts;

- the perimeter dike of the polder was damaged on an appreciable length;

- were destroyed under the hydrotechnical node; energy dissipator and its resilience;

- the installations from the manoeuvring towers were vandalized, not being provided with secure metal cabins for the prevention of these phenomena;

- the bridges with the insufficient drainage section were affected, some being even completely destroyed (S.C. AQUAPROIECT S.A, 2006).

The main objectives of the paper are the modelling of the water course with the forecast of the evolution of water levels over time as well as the possibility of making flood risk maps.

\section{DATA AND METHODS}

\subsection{Data used.}

The general slope of the land per emissary, on the projected sector is $1.55 \%$. There are 10 tributaries on this sector, of which 4 on the right and 6 on the left, most of them located upstream of the Ghertenis Polder.

In April 2005 there was an appreciable flood on the Barzava River (the largest in the last ten years), being registered at P.H.Moniom (located about 5 kilometers from Resita). The maximum flow recorded was $153 \mathrm{~m} 3 / \mathrm{s}$ - corresponding to an insurance with a probability of $5 \%$.

Capable storage volume of the Ghertenis polder:

- for the $1 \%$ insurance it is 17.7 million $\mathrm{m} 3$

- at the 5\% insurance it is 6.3 million $\mathrm{m} 3$

The maximum effluent flows in the Ghertenis Section as a result of the mentioned accumulations are reduced as follows:

- at $1 \%$ insurance it is from $322 \mathrm{~m} 3 / \mathrm{s}$ to $134 \mathrm{~m} 3 / \mathrm{s}$

- at the $5 \%$ insurance it is from $214 \mathrm{~m} 3 / \mathrm{s}$ to $120 \mathrm{~m} 3 / \mathrm{s}$

The Ghertenis polder in the current construction, with the two compartments, in the situation in which they will be put in normal operation, ensures the reduction of the maximum flows downstream of its section as follows:

- at the $5 \%$ insurance;

from $167 \mathrm{~m} 3 / \mathrm{s}$ to $82.4 \mathrm{~m} 3$, storing $9.28 \mathrm{mil} . \mathrm{mc}$

$-2 \%$ insurance 
from $229.24 \mathrm{~m} 3$ / s to $94.6 \mathrm{~m} 3$ / s, storing 15.41 thousand $\mathrm{m} 3$;

- at $1 \%$ insurance

from $274.2 \mathrm{~m} 3 / \mathrm{s}$ to $128.14 \mathrm{~m} 3 / \mathrm{s}$, storing $17.7 \mathrm{mil} . \mathrm{mc}$.

In the section of the Gataia hydrotechnical station, following the attenuation of the polder located upstream, the maximum flows are reduced to the following values:

- at the insurance of $5 \% 81.8 \mathrm{~m} 3 / \mathrm{s}$ (from $165 \mathrm{~m} 3 / \mathrm{s}$ in regime without polder)

- at the insurance of $2 \% 93.5 \mathrm{~m} 3 / \mathrm{s}$

- at the insurance of $1 \% 124.8 \mathrm{~m} 3 / \mathrm{s}$

\subsection{Methods}

MIKE 11 is a professional engineering software package for simulation of onedimensional flows in estuaries, rivers, irrigation systems, channels and other water bodies. MIKE 11 is a 1-dimensional river model. It was developed by DHI Water • Environment $\bullet$ Health, Denmark.

The Hydrodynamic Module (HD), which is the core component of the model, contains an implicit finite-difference 6-point Abbott-Ionescu scheme for solving the Saint-Venant's equations. The formulation can be applied to branched and looped networks and flood plains. HD module provides fully dynamic solution to the complete nonlinear 1-D Saint Venant equations, diffusive wave approximation and kinematic wave approximation, Muskingum method and Muskingum-Cunge method for simplified channel routing. It can automatically adapt to subcritical flow and supercritical flow. It has ability to simulate standard hydraulic structures such as weirs, culverts, bridges, pumps, energy loss and sluice gates (Beilicci et al., 2015).

The MIKE 11 is an implicit finite difference model for one dimensional unsteady flow computation and can be applied to looped networks and quasi-two dimensional flow simulation on floodplains. The model has been designed to perform detailed modeling of rivers, including special treatment of floodplains, road overtopping, culverts, gate openings and weirs. MIKE 11 is capable of using kinematic, diffusive or fully dynamic, vertically integrated mass and momentum equations. Boundary types include Q-h relation, water level, discharge, wind field, dam break, and resistance factor. The water level boundary must be applied to either the upstream or downstream boundary condition in the model. The discharge boundary can be applied to either the upstream or downstream boundary condition, and can also be applied to the side tributary flow (lateral inflow). The lateral inflow is used to depict runoff. The Q-h relation boundary can only be applied to the downstream boundary. MIKE 11 is a modeling package for the simulation of surface runoff, flow, sediment transport, and water quality in rivers, channels, estuaries, and floodplains (***, 2012).

MIKE 11 has long been known as a software tool with advanced interface facilities. Since the beginning MIKE11 was operated through an efficient interactive menu system with systematic layouts and sequencing of menus. It is within than framework where the latest 'Classic' version of MIKE 11 - version 3.20 was developed.

The new generation of MIKE 11 combines the features and experiences from the MIKE 11 'Classic' period, with the powerful Windows based user interface 
including graphical editing facilities and improved computational speed gained by the full utilization of 32-bit technology.

The computational core of MIKE 11 is hydrodynamic simulation engine, and this is complemented by a wide range of additional modules and extensions covering almost all conceivable aspects of river modeling.

MIKE 11 has been used in hundreds of applications around the world. Its main application areas are flood analysis and alleviation design, real-time flood forecasting, dam break analysis, optimization of reservoir and canal gate/structure operations, ecological and water quality assessments in rivers and wetlands, sediment transport and river morphology studies, salinity intrusion in rivers and estuaries (Cristian et al., 2018).

\section{RESULTS AND DISCUSSIONS}

Numerical modelling was performed with the program MIKE11. Site plan with the network model in this situation is shown in Figure 1.

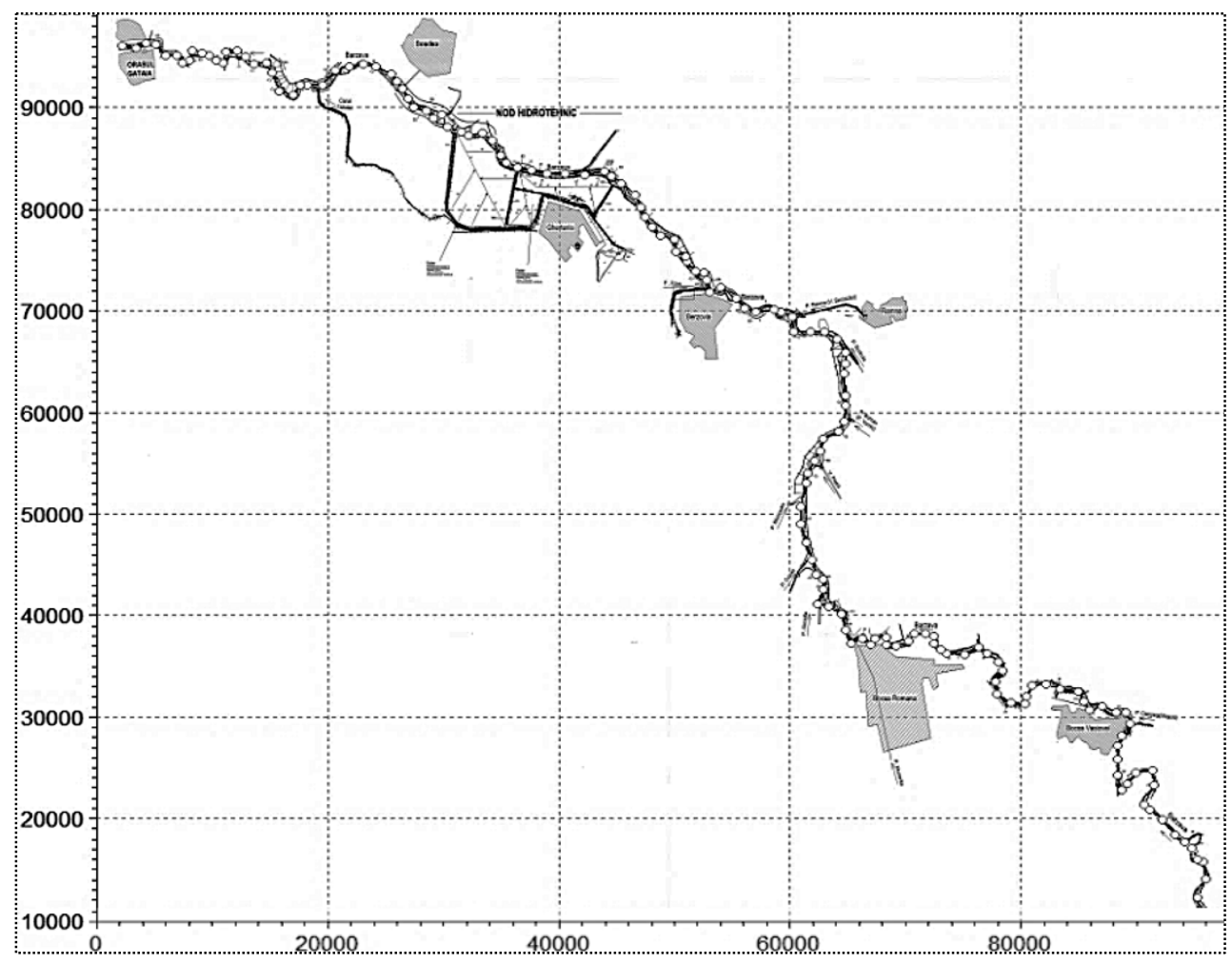

Fig. 1. Plan view with the Bârzava river network model.

Cross sections through the channel as topographical surveys are shown in Figure 2. 


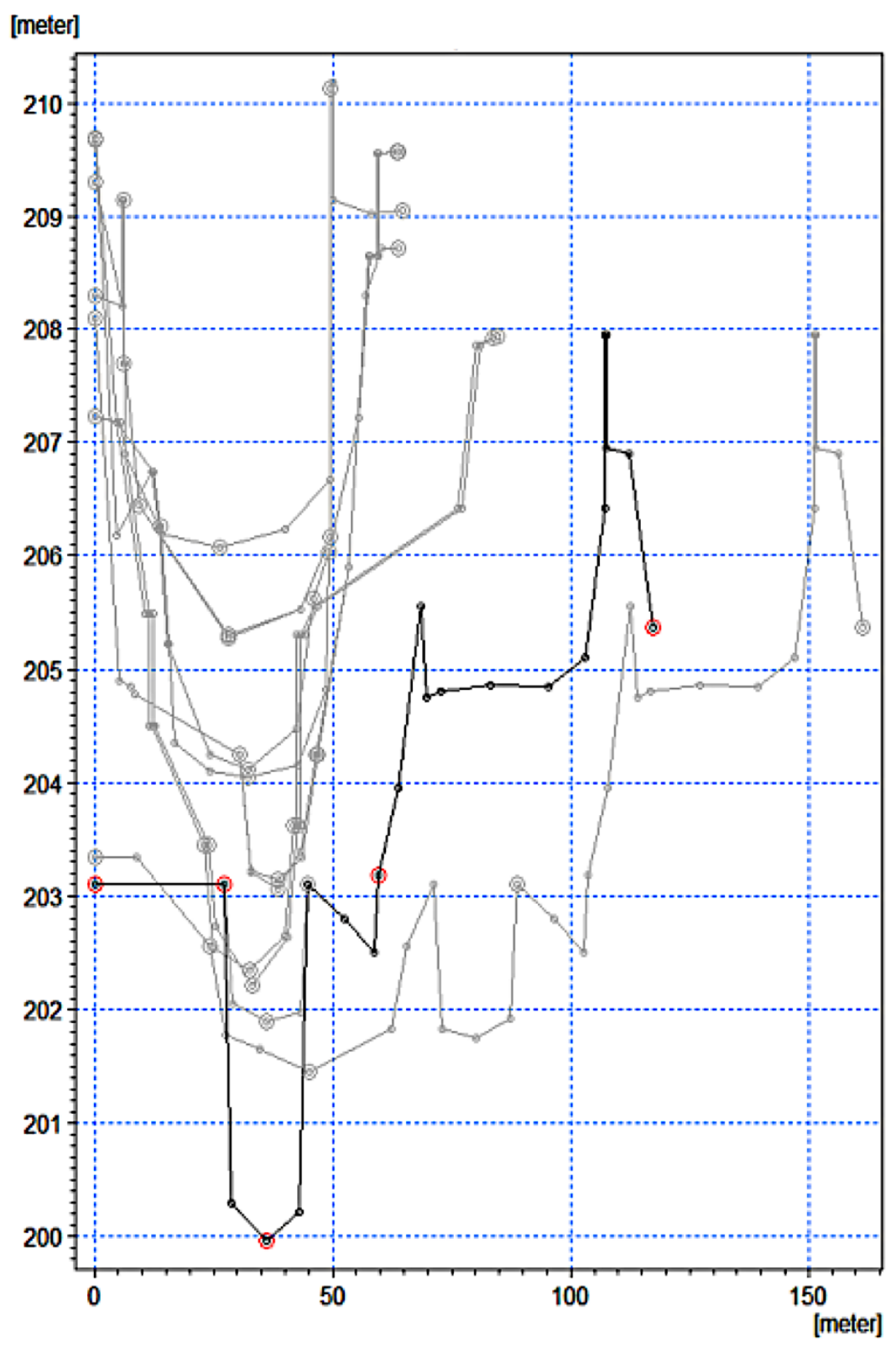

Fig. 2. Cross sections along Bârzava river longitudinal profile.

According to data entry or formulated boundary conditions, namely the upstream inflow at chainage 0 are a Discharge Hydrograph (presented in Figure 3) and in the downstream at chainage 1037 curve key for downstream section of the river. 


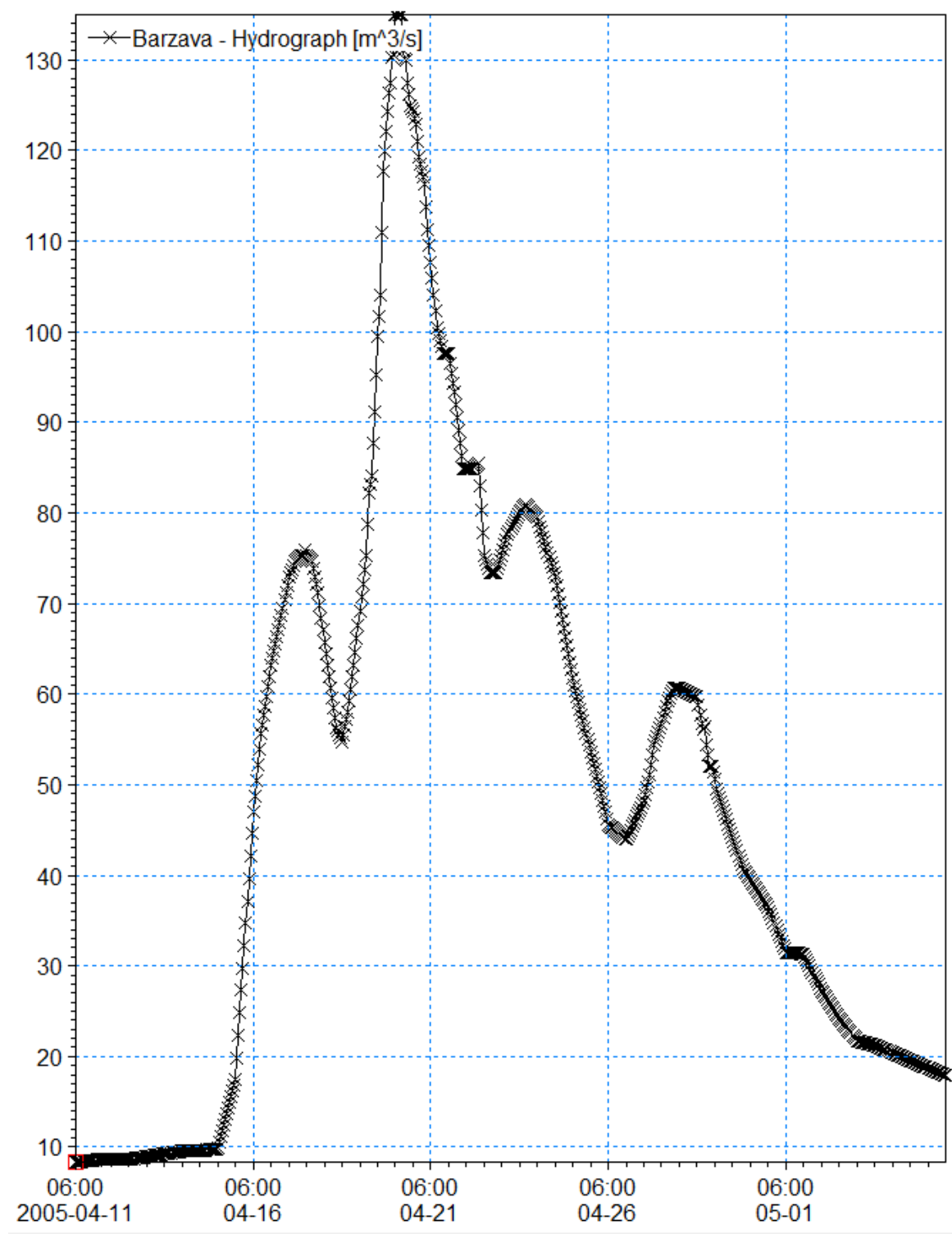

Fig. 3. Discharge Hydrograph of the upstream inflow at chainage 0.

After running the program MIKE11, through existing channel longitudinal profile, water levels along the channel was obtained (Figure 4).

The results obtained in terms of river water levels were verified with the water levels measured following the flood wave, which made it possible to calibrate the model. With the calibrated and validated model, simulations of possible floods can be performed at different flow scenarios. 


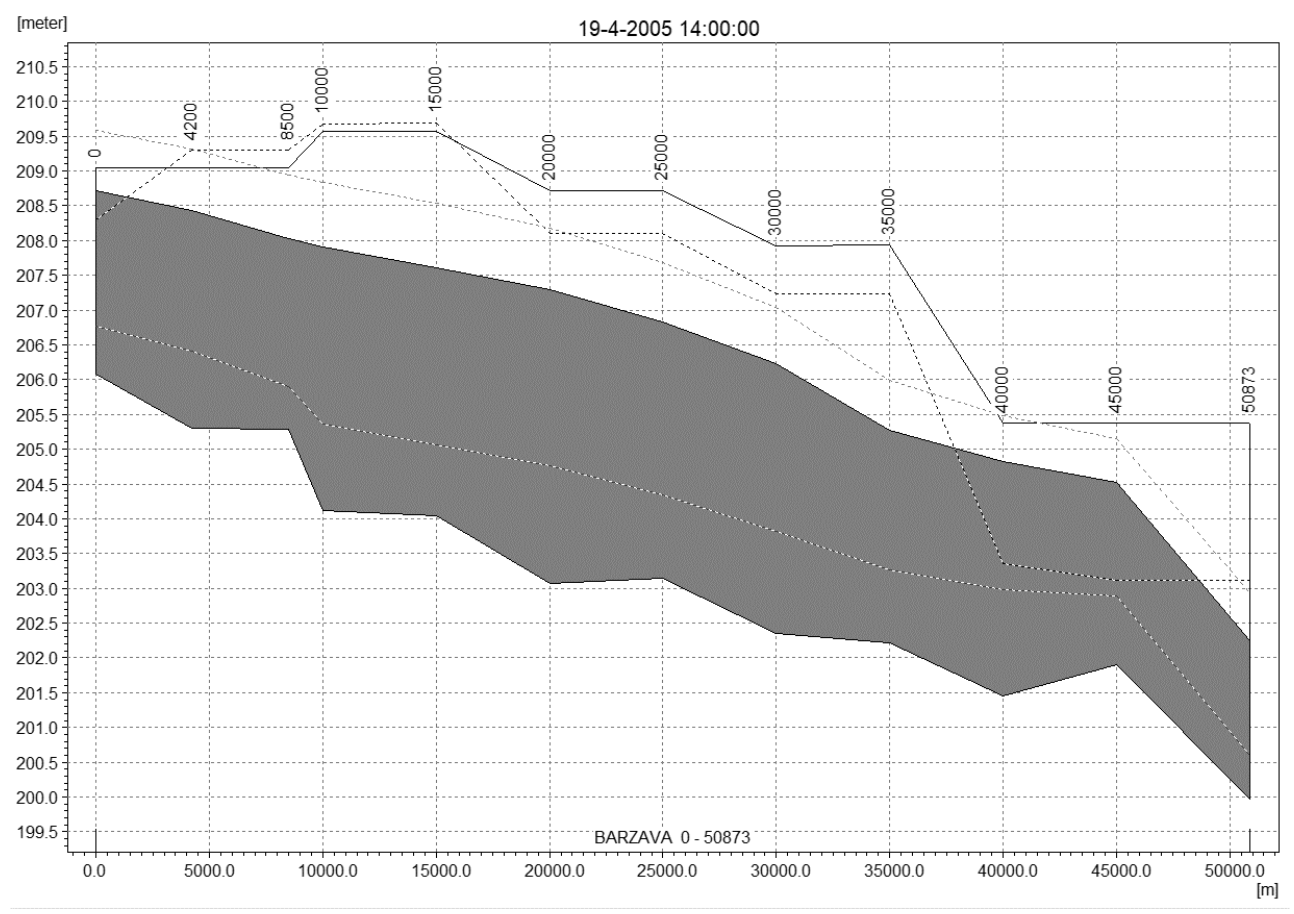

Fig. 4. Longitudinal profile, water levels with min. and max.

\section{CONCLUSIONS}

This study presents the application of a 1-dimensional unsteady flow hydraulic model used for the simulation of flow in rivers: the MIKE 11 model from the Danish Hydraulic Institute (DHI). MIKE 11 is the preferred choice of professional river engineers when reliability, versatility, productivity and quality are the keywords (Hausler-Cozma et al., 2018).

Besides the models mentioned above, have been developed over the years other models applied in the preparation of flood risk maps. In Romania, most flood risk maps were prepared using HEC-RAS and MIKE 11 models, which show a high degree of confidence (Armas et al., 2017).

Throughout the Community Countries different types of floods occur, such as river floods, flash floods, urban floods and floods from the sea in coastal areas. The damage caused by flood events may also vary across the countries and regions of the Community. Hence, objectives regarding the management of flood risks should be determined by the Member States themselves and should be based on local and regional circumstances. In each river basin district or unit of management the flood risks and need for further action should be assessed. In order to have available an effective tool for information, as well as a valuable basis for priority setting and further technical, financial and political decisions regarding flood risk management, it is necessary to provide for the establishing of flood hazard maps and flood risk maps showing the potential adverse consequences 
associated with different flood scenarios, including information on potential sources of environmental pollution as a consequence of floods David et al (***, 2007).

Member States should assess activities that have the effect of increasing flood risks. Flood risk management plans should therefore take into account the particular characteristics of the areas they cover and provide for tailored solutions according to the needs and priorities of those areas, whilst ensuring relevant coordination within river basin districts and promoting the achievement of environmental objectives laid down in Community legislation. Member States should base their assessments, maps and plans on appropriate 'best practice' and 'best available technologies' not entailing excessive costs in the field of flood risk management.

\section{ACKNOWLEDGEMENTS}

This paper can be possible thanks to project: Development of knowledge centers for life-long learning by involving of specialists and decision makers in flood risk management using advanced hydroinformatic tools, AGREEMENT NO LLP-LdV-ToI2011-RO-002/2011-1-RO1-LEO05-5329. This project has been funded with support from the European Commission. This publication [communication] reflects the views only of the author, and the Commission cannot be held responsible for any use which may be made of the information contained therein.

\section{REFERENCES}

1. Directive 2007/60/EC of the European Parliament and of the Council of 23 October 2007 on the assessment and management of flood risks;

2. David, I.; Nagy, Z; Beilicci, E.; Kramer, T.; Szilagyi, A, "Development of knowledge centers for life-long learning by involving of specialists and decision makers in flood risk management using advanced hydroinformatic tools", Lifelong Learning Programme Leonardo da Vinci, Submission ID 260243, Submission local date (Brussels), 2011-02-28, Hash code 5BA440F7658CABFE, Form id. 5BA440F7;

3. $* * *$ Mike 11 User Guide, Holland, pp 1-542, 2012;

4. $\quad * * *$ S.C. AQUAPROIECT S.A., Project 60057/2006.

5. Hausler-Cozma D.P., Beilicci E., Beilicci R. (2018), Modeling of Water Quality Evolution with Advanced Hydroinformatic Tool. Study Case: Bega Channel Sector, 4th World Multidisciplinary Civil Engineering-Architecture-Urban Planning Symposium - WMCAUS, Czech Republic, DOI: 10.1088/1757-899X/603/4/042027;

6. Cristian G., Beilicci R., Beilicci E. (2018), Advance Hydraulic Modelling of Maciovita River, Caras Severin County, Romania, 4th World Multidisciplinary Civil Engineering-Architecture-Urban Planning Symposium - WMCAUS, Czech Republic, DOI: 10.1088/1757-899X/471/4/042001;

7. Armas A., Beilicci R., Beilicci E. (2017), Numerical Limitations of 1D Hydraulic Models Using MIKE11 or HEC-RAS software - Case study of Baraolt River, Romania, 4th World Multidisciplinary Civil Engineering-Architecture-Urban Planning Symposium - WMCAUS, Czech Republic, DOI: 10.1088/1757-899X/245/7/072010;

8. Beilicci E., Beilicci R. (2015), Flash Floods - Causes, Effects, Possibilities Of Modelling With Hydroinformatic Tools, Water Resources, Forest, Marine And Ocean Ecosystems, SGEMM 2015, VOL I, Bulgaria, WOS: 000371663400040. 